\title{
FORMAÇÃO INICIAL DE PROFESSORES DE BIOLOGIA: A METODOLOGIA COLABORATIVA MEDIADA PELO COMPUTADOR E A APRENDIZAGEM PARA A DOCÊNCIA
}

\author{
Pre service education of biology teachers: \\ the computer-mediated collaborative methodology \\ and learning for teaching
}

\author{
Dulcinéia Ester Pagani Gianotto ${ }^{1}$ \\ Renato Eugênio da Silva Diniz ${ }^{2}$
}

\begin{abstract}
Resumo: Este artigo apresenta os resultados da implantação e aplicação da metodologia colaborativa mediada pelo computador desenvolvida com alunos de Prática de Ensino de Biologia da UEM. Apoiando-se na abordagem qualitativa, os dados foram coletados em questionários, documentos e observações, e a análise sobre as ideias, concepções e reflexões dos sujeitos da pesquisa processou-se de acordo com três grupos de elementos formativos para docência - construindo a identidade profissional, construção do conhecimento compartilhado e mediação. Concluiu-se que os Alunos-Professores (AP) passaram por significativas mudanças atitudinais com relação ao processo de ensino-aprendizagem e ao papel do professor, na medida em que, ao compreenderem a importância de se valorizar o uso da metodologia colaborativa e do computador, como recurso pedagógico no ensino-aprendizagem de Biologia, contemplando-os na experiência vivida, construíram saberes para a docência.
\end{abstract}

Palavras-chave: Metodologia colaborativa. Computador. Formação inicial. Docência.

Abstract: This article presents the results of the implantation and application of a computer-mediated collaborative methodology applied to Biology students at Practicum Internship course at the Universidade Estadual de Maringá. Based on qualitative approach, data was collected through questionnaires, documents, in locus observations and analysis of ideas. The conceptions and participants reflections was processed according to three groups of formative elements to teaching - constructing a professional identity, construction of shared knowledge and mediation. It follows that student-teachers (ST) had significant attitudinal changes regarding the teaching-learning process and concerning the teacher role, as they embrace the importance of appreciate the collaborative methodology and the use of computers as a pedagogical resource in Biology teaching-learning, contemplating this items on their own experience, they were able to constructed knowledge for teaching.

Keywords: Collaborative methodology. Computer. Pre-service education. Teaching.

${ }^{1}$ Licenciatura em Ciências Biológicas, doutora em Educação para a Ciência. Docente, Departamento de Biologia, Universidade Estadual de Maringá. Maringá, PR, Brasil. <mgianoto@teracom.com.br>

${ }^{2}$ Licenciatura em Ciências Biológicas, livre docente em Educação para a Ciência. Diretor, Instituto de Biociências da Universidade Estadual Paulista, campus de Botucatu. Botucatu, SP, Brasil.

<rdiniz@ibb.unesp.br>

${ }^{1}$ Rua Silva Jardim, 190, apto. 8

Centro - Maringá, PR

87.013-010 


\section{Introdução}

A disciplina Prática de Ensino, como marco na formação inicial de professores, pode ter grande influência no processo de desenvolvimento profissional dos Alunos-Professores $\left(\mathrm{AP}^{3}\right)$ ao propor, por exemplo, o uso de práticas pedagógicas inovadoras. Entretanto, a literatura especializada tem mostrado que os professores de Prática de Ensino têm se deparado com inúmeros desafios e dificuldades na busca de novas pedagogias nos cursos de formação de professores (PICONEZ, 2005), particularmente no que diz respeito ao uso das tecnologias computacionais.

Entende-se que é responsabilidade da Prática de Ensino articular meios para que o aluno em formação vivencie situações nas quais a informática seja usada como recurso educacional, a fim de poder entender o que significa o aprendizado com o auxílio "da informática, qual o seu papel como educador nessa situação, e que metodologia é mais adequada ao seu estilo de trabalho" (VALENTE, 1998, p. 4). Para esse autor, durante o processo de formação, é preciso prever um espaço para que os alunos passem a entender e dominar o computador, propiciando um conhecimento sólido nas áreas de psicologia do desenvolvimento, ciência da educação, ciência da computação e tecnologia educacional. Dessa forma, o futuro professor não só estará apto a desenvolver atividades que integrem a informática e a educação, como, também, a partir dessa experiência, apto a refletir e, quem sabe, conscientemente, assumir uma nova postura como educador que utiliza a informática em educação.

Além de atualizar os conhecimentos científicos, de buscar a descoberta de novos materiais e novas metodologias pedagógicas, o futuro professor necessita também de espaço para a reflexão sobre o fazer pedagógico por meio de leituras, pesquisas específicas e trocas de experiências (MENDES; MUNFORD, 2005), para que possa desenvolver habilidades de trabalhar em equipe. Portanto, o bom desempenho do exercício da profissão de professor exige, além de saberes teóricos (conteúdos), conhecimentos, habilidades, competências e saberes específicos da docência.

Nos cursos de licenciatura, a disciplina Prática de Ensino é fundamental, e o seu maior desafio é colaborar no sentido de fazer o aluno enxergar-se, de fato, como professor. É preciso, então, que esta disciplina proporcione, durante o processo de formação inicial, oportunidades teórico-práticas, para que os AP elaborem os saberes da docência, levando-os, assim, a construírem a sua própria identidade profissional. O professor de Prática de Ensino deve criar um ambiente de ensino-aprendizagem ${ }^{4}$ que, além de contemplar as inovações tecnológicas, tenha, como essência: o diálogo, a colaboração, a troca, a descoberta e a reflexão.

Assim pensando, ao iniciar o doutorado em educação contemplando, como objeto de estudo, a formação inicial de professores, me interessei por desenvolver uma pesquisa que

\footnotetext{
${ }^{3}$ Utilizamos a expressão alunos-professores (AP) para designar os participantes da pesquisa, todos graduandos do curso de licenciatura em Biologia da UEM.

${ }^{4}$ A resolução CNE/CP n ${ }^{\circ}$ 1/2002 (CONSELHO NACIONAL DE EDUCAÇÃO, 2002) sugere que a formação para a atividade docente deve contemplar "o uso de tecnologias da informação e da comunicação" (Art. $2^{\circ}$., VI) e promover "o desenvolvimento de hábitos de colaboração e de trabalho em equipe" (Art. 2., VII).
} 
abordasse a questão específica de como "formar o futuro docente para utilizar o computador no ensino de Biologia dentro de uma perspectiva colaborativa".

A observação de que computadores e colaboração estão relacionados é consenso entre vários autores. A literatura registra que inúmeras pesquisas propõem e discutem a utilização do computador sob uma perspectiva colaborativa de forma variada, nos diversos níveis de ensino e em diversas disciplinas (CROOK, 1996; CORTELAZZO, 2000; SOUZA, 2000).

Como professora de Prática de Ensino de Ciências e Biologia, desde 1989, na Universidade Estadual de Maringá, tenho constatado, assim como Gunstone e Northfield, (1994), Behrens (1996) e Pimenta (2005), que, no estágio supervisionado, os AP, frutos de uma educação que produz uma aprendizagem mecânica e procedimental, apresentam tendência a reproduzir essas metodologias, resistindo à introdução de inovações conceituais e operacionais em sala de aula. Dentre as resistências observadas, destaca-se, sobretudo, o emprego de tecnologias, como, por exemplo, o computador. Diante desta realidade, vislumbrei a possibilidade de contribuir para reverter esse quadro, buscando uma maneira de oportunizar, aos AP, a incorporação de uma abordagem educacional que lhes proporcionasse, além do domínio de elementos teóricos específicos, enfocar o ensino de Biologia, contemplando o uso das ferramentas computacionais dentro de uma perspectiva colaborativa.

Portanto, esta pesquisa teve, como questão norteadora, verificar em que medida a vivência de uma prática colaborativa (adaptado de BEHRENS, 2003) mediada pelo computador, durante a disciplina Prática de Ensino, pode contribuir para a formação inicial de professores de Biologia (a aprendizagem da docência).

O objetivo principal deste artigo é descrever os resultados da pesquisa ${ }^{5}$, desenvolvida durante a formação inicial de um grupo de $16 \mathrm{AP}^{6}$ da disciplina Prática de Ensino do curso de Ciências Biológicas da Universidade Estadual (UEM) de Maringá-PR.

\section{Formação inicial de professores: uso do computador e prática colaborativa}

Até pouco tempo, a formação de professores tinha, como ponto central, especialmente, o conhecimento acerca da disciplina, e os professores assumiam-se como transmissores de conhecimento científico. As questões de ordem pedagógica ou relativa à prática docente eram pouco valorizadas (FIORENTINI; SOUZA JR.; MELO, 2001).

\footnotetext{
${ }^{5}$ Gianotto (2008), pesquisa autorizada pelo Comitê de Ética da UEM.

${ }^{6}$ A disciplina Prática de Ensino integra o currículo do Curso de Licenciatura em Ciências Biológicas da UEM. Todos os AP leram o Termo de Consentimento Livre e Esclarecido e concordaram, espontaneamente, em participar da pesquisa. Os dados coletados em questionários nominais, observação e outros documentos (diários, gravação em vídeo e produção de textos individuais e coletivos) foram recolhidos e avaliados, diretamente, pela pesquisadora, professora de Prática de Ensino da UEM.
} 
Para Nóvoa (1998, p. 30), “Quem sabe, faz; quem compreende, ensina”. Este autor considera um insulto imaginar o processo de ensino como uma simples transposição do saber científico para o conhecimento escolar, e pondera, afirmando que o professor deve não apenas dominar a matéria que ensina, mas também compreender a maneira como o conhecimento se constitui historicamente.

Nos dias de hoje, esta é uma exigência que tem relação direta com o impacto das transformações econômicas, políticas, sociais e culturais na Educação e no ensino, reconhecido pelos educadores, e engendrando uma reavaliação do papel da escola e dos professores, cuja formação assume importância fundamental, afinal os docentes precisam estar aptos a formar cidadãos participantes da sociedade da informação, que exige um novo perfil de profissional, “[...] um indivíduo crítico, criativo, com capacidade de pensar, de aprender a aprender, de trabalhar em grupo, de utilizar os meios automáticos de produção e disseminação da informação e de conhecer o seu potencial cognitivo, afetivo e social" (SIMIÃO; REALI, 2002, p. 128).

Porém, é consenso entre educadores (GUNSTONE; NORTHFIELD, 1994; LIBÂNEO, 2000; FREITAS; VILLANI, 2002; MIZUKAMI, 2002; AZZI, 2005), que o tipo de formação a que estão submetidos, hoje, os professores, não contribui de forma satisfatória para que o aluno se desenvolva como pessoa autônoma e possa participar, como cidadão, de pleno direito num mundo cada vez mais exigente sob todos os aspectos. Uma sociedade que experimenta mudanças em suas formas de se organizar, de divertir-se, de ensinar e de aprender, nas escolas, necessita de pessoas que modifiquem estruturas arcaicas e autoritárias de ensino (MORAN, 2003a). Daí a relevância da formação de professores. Assim, ao mesmo tempo em que se propõe uma nova educação escolar, um novo papel e um novo perfil de professor, estão sendo idealizados ao ter-se como:

[...] perspectiva a construção de novas estratégias de forma a incorporar as mudanças dos sistemas produtivos que exigem um novo perfil profissional capaz de localizar os desafios mais urgentes de uma sociedade "multimídia e globalizada", em que o rápido desenvolvimento, científico e tecnológico, impõe uma dinâmica de permanente reconstrução de conhecimento, saberes, valores e atitudes. (FREITAS; VILLANI, 2002, p. 1)

Acreditamos que a melhoria da qualidade de ensino passa, necessariamente, pela revisão dos padrões de formação de professores, pois a maioria dos cursos de licenciatura tem seus currículos apoiados na concepção de professor como um profissional que deverá aplicar conhecimentos adquiridos em situações específicas e, portanto, não forma o professor capaz de ensinar o aluno a pensar. Segundo Libâneo (2000), hoje, o professor precisaria, no mínimo, de: uma cultura geral mais ampla, capacidade de aprender a aprender, competência para saber agir na sala de aula, habilidades comunicativas, domínio da linguagem informacional, saber usar meios de comunicação e articular as aulas com as mídias e multimídias. Para tanto, o autor destaca seis posturas necessárias ao novo docente: assumir o ensino como mediação; conhecer estratégias do ensinar a pensar, ensinar a aprender a aprender (provendo os meios de autoconstrução do conhecimento pelos alunos e se empenhando em auxiliar os alunos a pensarem os conteú- 
dos a partir de uma perspectiva crítica); assumir o trabalho de sala de aula como um processo comunicacional; reconhecer o impacto das Tecnologias de Informação e Comunicação (TIC) (na educação escolar e na vida cotidiana), e integrar, no exercício da docência, a dimensão afetiva.

A interação, o ensinar a pensar, a busca da perspectiva crítica dos conteúdos, o desenvolvimento da capacidade comunicativa, o reconhecimento (e, sobretudo, a aceitação) do impacto das TCI, são aspectos que devem ser trabalhados já na formação inicial dos professores. Quanto ao uso do computador, Tajra (2001) afirma que as vantagens desse uso, por grupos de estudantes, num ambiente ativo, possibilitam a troca de ideias, entre si e entre os grupos, propiciando a construção do aprendizado coletivo e em equipe, sendo as habilidades desenvolvidas de forma o mais natural possível, sob o gerenciamento do professor.

Isto reforça o papel do professor, que deve deixar de ser apenas o repassador de conhecimentos - o computador pode fazer isto de modo eficiente - e passar a ser o criador de situações de aprendizagem e o mediador do processo de desenvolvimento intelectual do aluno (VYGOTSKY, 1984; PALANGANA, 2001; BEHRENS, 2003; MORAN, 2003a; OLIVEIRA, 2003). Ao fazer o aluno usar o computador como uma ferramenta educacional - isto é, um instrumento com o qual possa desenvolver algo e, portanto, aprender pelo fato de estar executando uma tarefa por intermédio de suas ferramentas -, ao professor cabe elaborar atividades significativas que serão desenvolvidas para atingir objetivos preestabelecidos e desejados (VALENTE, 1998).

No que diz respeito ao ensino de Biologia, são conhecidas as dificuldades que muitos alunos apresentam na compreensão dos fenômenos físicos, químicos e biológicos. Aprender Biologia é muito mais do que decorar nomes, conceitos, definições e esquemas. Aprender Biologia significa, especialmente, reconhecer os processos que ocorrem na natureza, interpretando-os e relacionando-os ao seu dia a dia. Assim, na tentativa de fugir do ensino livresco, acreditamos que determinadas ferramentas computacionais, sugeridas por alguns autores (VALENTE, 1998; MASETTO, 2003; MORAN, 2003b), para utilização na educação, podem ser também extremamente úteis ao processo de ensino-aprendizagem de Biologia. Uma modalidade bastante significativa para ser utilizada nas aulas de Biologia é a simulação, por meio da qual, conteúdos como síntese de proteínas, duplicação de DNA (ácido desoxirribonucléico) e divisão celular podem ser abordados, eficientemente, potencializando o aprendizado do aluno, se a execução da(s) tarefa(s) for(em) realizada(s) por grupos colaborativos, isto é, em situações que permitam ocorrer aprendizagem colaborativa. Afinal, segundo Vygotsky (1984), é pela aprendizagem nas relações com os outros que construímos os conhecimentos que permitem nosso desenvolvimento mental, impulsionado pela interferência na Zona de Desenvolvimento Proximal (ZDP).

Segundo Varella et al. (2002), embora a aprendizagem colaborativa não prescinda da tecnologia para ser adotada, acredita-se que essa amplifica sua possibilidade e potencializa as situações nas quais os professores e alunos, e esses, entre si, pesquisem, discutam, se relacionem e construam suas trajetórias individuais e coletivas com o conhecimento. Ampliando essa visão, Bruffee (1999) lança um olhar comunicativo para o computador, coerente com seu ponto de vista de que o conhecimento é uma construção social continuamente inventada e reinventada. 
Alunos que reúnem-se em torno de um computador para explicar assuntos uns aos outros estão aprendendo de forma colaborativa. Cientistas e engenheiros trabalhando para fixar robôs exploradores em Marte estão aprendendo de forma colaborativa. A rede mundial de computadores (world wide web) é colaborativa de um ponto a outro. (BRUFFEE, 1999, p. 113)

O uso adequado da tecnologia computacional pode auxiliar os processos de ensinoaprendizagem, porém, o êxito nas tarefas mediadas por essa tecnologia implica ênfase na troca entre os participantes acerca do que se aprendeu acessando os recursos da informática, indo além da mera utilização da tecnologia como recurso didático, ou seja, avançando para uma compreensão dos limites da interação virtual e privilegiando a interação face a face, isto é, de ideias, experiências e conhecimentos adquiridos. Segundo Vygotsky (1984), o desenvolvimento é um processo sociocultural que ocorre por meio das interações sociais e demanda cooperação/colaboração ${ }^{7}$; as interações colaborativas podem contribuir para o desenvolvimento de processos cognitivos, pois o desenvolvimento do pensamento segue um curso que vai do social para o individual.

Johnson e Johnson (1987) sustentam que relações de estudantes em grupo contribuem de vários modos para a socialização e o desenvolvimento cognitivo. Para Crook (1996), o conhecimento socialmente compartilhado é relevante para a aprendizagem, já que as interações colaborativas podem concorrer para a construção do conhecimento compartilhado.

\section{A pesquisa}

A pesquisa se apoiou na abordagem qualitativa (LÜDKE; ANDRÉ, 1986). Foi realizada de abril a novembro de 2006, em duas etapas: implantação da prática colaborativa mediada pelo computador, durante as atividades desenvolvidas na disciplina Prática de Ensino (abril a agosto) e, posteriormente, aplicação dessa prática, pelos AP, numa aula de Biologia no Ensino Médio (setembro a novembro). O ambiente real dos AP, sujeitos da pesquisa, foi constituído pelos locais onde ocorreram os fenômenos pedagógicos relacionados à formação docente de Biologia: o laboratório de inclusão digital do Museu Dinâmico Interdisciplinar (MUDI), sala de aula da UEM (primeira etapa), e o laboratório de informática do Instituto de Educação Estadual de Maringá (IEE), escola campo do Estágio Supervisionado (segunda etapa).

\footnotetext{
${ }^{7}$ Via de regra, a distinção entre os termos colaboração e cooperação não é vista como necessária, pois independente do termo que se use, o importante é compreender que "[...] educar é colaborar para que professores e alunos, nas escolas e organizações, transformem suas vidas em processos permanentes de aprendizagem. É ajudar os alunos na construção de sua identidade, do seu caminho pessoal e profissional, do seu projeto de vida, no desenvolvimento das habilidades de compreensão, emoção e comunicação que lhes permitam encontrar seus espaços pessoais, sociais e profissionais e tornar-se cidadãos realizados e produtivos" (MORAN, 2003a, p. 13).
} 
Participaram da pesquisa 16 AP: 12 do sexo feminino e quatro do masculino, na faixa etária entre 21 e 24 anos de idade. Todos, acadêmicos ${ }^{8}$, regularmente matriculados na disciplina Prática de Ensino de Ciências Físicas e Biológicas e Biologia II, no quarto ano, período integral, do curso de Ciências Biológicas, modalidade licenciatura, da UEM. Portanto, são objeto de análise desta pesquisa: as ações e falas, os depoimentos e diálogos, assim como as reflexões dos AP sobre as atividades desenvolvidas. Dessa forma, os dados do estudo consistem nos registros dos avanços, dificuldades e impressões sobre a vivência dos AP envolvidos na investigação.

A coleta de dados, organizada por meio de um conjunto de ações pedagógicas (Quadro 1), elaboradas a partir da aplicação e análise de um questionário (momento 1), e planejadas e processadas durante quase toda a prática (momentos 2, 3, 4 e 5), utilizou questionários (Q1 e Q2), observação e produção de documentos (diários, gravação em vídeo e produção de textos individuais e coletivos). Das fontes documentais “[...] podem ser retiradas evidências que fundamentem afirmações e declarações do pesquisador [...] surgem num determinado contexto e fornecem informações sobre esse mesmo contexto" (LÜDKE; ANDRÉ, 1986, p. 39). Assim, os registros das observações, impressões, sentimentos e ideias foram documentados, sobretudo nos diários de aula: diário da professora/pesquisadora e diário do aluno (OSPINA, 2005).

Quadro 1. Organização das ações pedagógicas para coleta de dados.

\begin{tabular}{|c|c|}
\hline $1^{\mathrm{a}}$. etapa (abril a agosto - MUDI) & $2^{a}$. etapa (setembro a novembro - IEE) \\
\hline $\begin{array}{l}\text { Momento } 1 \text { - caracterização dos AP (Q1) - importân- } \\
\text { cia da pesquisa - organização e responsabilidade - } \\
\text { ensino de Ciências e Biologia - o computador nas es- } \\
\text { colas (sala de aula/UEM) } \\
\text { Momento } 2 \text { - fundamentação teórica: os paradigmas } \\
\text { da educação - ousadia e autonomia, como caracterís- } \\
\text { ticas do professor - ensino e aprendizagem de Biolo- } \\
\text { gia - o diário de aula como instrumento de reflexão - } \\
\text { aprendizagem colaborativa (Lab. de Inf. MUDI) } \\
\text { Momento } 3 \text { - suporte teórico-prático: informática edu- } \\
\text { cacional - trabalho de campo - elaboração e argumen- } \\
\text { tação de um planejamento prévio contemplando a prá- } \\
\text { tica colaborativa e o uso do computador (Lab.Inf. MUDI, } \\
\text { escolas públicas e privadas) }\end{array}$ & $\begin{array}{l}\text { Momento } 4 \text { - reconhecimento da escola campo de } \\
\text { estágio - aula de Biologia com o uso do computador } \\
\text { sob uma perspectiva colaborativa (Lab. de Inf. IEE) } \\
\text { Momento } 5 \text { - análise, reflexão e sugestões dos AP - } \\
\text { Q2 (sala de aula/UEM) }\end{array}$ \\
\hline
\end{tabular}

Em se tratando de pesquisa qualitativa, a análise dos dados consistiu da explicação da realidade. Nas ações, nos diálogos e, particularmente, nas reflexões nos diários de aula dos AP e da professora/pesquisadora, registradas no decorrer das atividades (momentos 2 ao 5),

\footnotetext{
${ }^{8}$ Embora os acadêmicos tenham concordado em participar espontaneamente da pesquisa, alguns deles ofereceram resistência ou tiveram dificuldades para aderir à metodologia colaborativa e ao uso do computador, havendo necessidade de muito esforço e dedicação, por parte da pesquisadora, no sentido de conscientizá-los e incentivá-los, durante toda a investigação.
} 
buscou-se “evidências” (LÜDKE; ANDRÉ, 1986) de que o desenvolvimento de ações pedagógicas, fundamentadas nas diretrizes teóricas da Aprendizagem Colaborativa (AC) (Figura 1) e associadas ao uso da tecnologia computacional, provocou uma mudança de atitude dos AP', influenciando-os a aderirem ao uso da metodologia colaborativa mediada pelo computador e contemplá-la no planejamento e aplicação de uma aula de Biologia em uma turma de alunos do Ensino Médio.

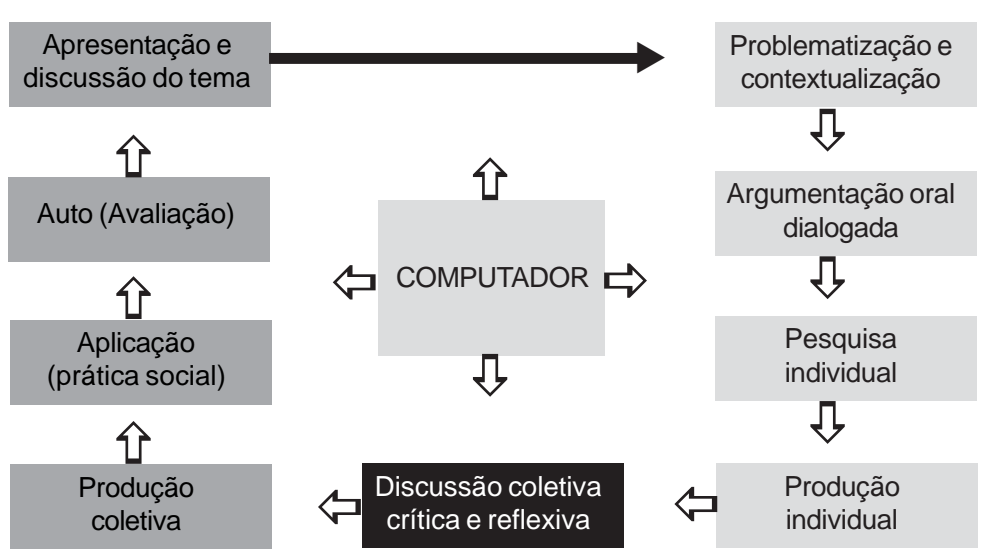

Figura 1. Síntese da Metodologia da Prática Colaborativa.

Fonte: Adaptado de Behrens (2003, p. 108-127).

A análise crítico-reflexiva dos resultados da pesquisa - realizada considerando o envolvimento e comprometimento dos AP com a proposta, as concepções elaboradas e as transformações evidenciadas, sobretudo na elaboração do planejamento e no desenvolvimento da aula de Biologia ${ }^{10}$ no Ensino Médio, dentro da proposta colaborativa mediada pelo computador como recurso pedagógico - mostrou algumas evidências de construção de saberes para a docência.

\footnotetext{
${ }^{9}$ A mudança de atitude dos AP foi gradativa, e ocorreu durante todo o desenvolvimento da prática, sendo observada nas ações, debates, diálogos, produções e reflexões registradas. Em alguns AP, esta mudança foi efetiva: no ano de 2007, de acordo com e-mails recebidos pela pesquisadora, eles já estavam exercendo a função de professores e utilizando a tecnologia computacional no Ensino Médio.

${ }^{10}$ Apesar de ter sido solicitado, aos AP, que elaborassem o planejamento da aula de Biologia dentro da metodologia colaborativa mediada pelo uso do computador, houve grupos que apresentaram dificuldades e, assim, necessitaram de uma segunda oportunidade - ocasião em que foi possível observar que optar por essa nova metodologia implicou erros e, consequentemente, incorporação e assimilação de novos conceitos e concepções que permitissem chegar à elaboração do planejamento solicitado, ou seja, bem diferente daquele que estavam habituados a fazer.
} 
Formação inicial de professores de Biologia: ...

\section{Resultados e discussão: algumas evidências de aprendizagem para a docência}

A atividade profissional docente traz, implícita ou explícita, uma série de habilidades e competências que favorecem os professores a ensinarem com eficiência (SIMIÃO; REALI, 2002). Neste sentido, os cursos de licenciatura devem formar professores capazes de se ajustar à realidade contemporânea mediante o desenvolvimento de "novas atitudes docentes" (LIBÂNEO, 2000, p. 28). Na mesma linha de pensamento, Gil-Pérez e Carvalho (2000, p. 19) apontam algumas "necessidades formativas do professor", e Perrenoud (2000, p. 14) elege "competências prioritárias", coerente com um novo papel do professor.

Assim, ao analisar a trajetória dos AP, durante a implantação e aplicação da metodologia colaborativa mediada pelo computador na formação inicial de professores de Biologia, foi possível observar que esta metodologia contribuiu, significativamente, na medida em que levou os AP a desenvolverem alguns elementos formativos importantes para a docência (GILPÉREZ; CARVALHO, 2000; LIBÂNEO, 2000; PERRENOUD, 2000), reunidos neste artigo em três grupos: construindo a identidade profissional, construção do conhecimento compartilhado e mediação como fator relevante no processo ensino-aprendizagem.

\section{Construindo a identidade profissional}

É consenso, entre pesquisadores (GUNSTONE; NORTHFIELD, 1994; BEHRENS, 1996; VIANNA; CARVALHO, 2001; FREITAS; VILLANI, 2002), que a formação inicial de professores caracteriza-se como um desafio, já que os AP resistem às mudanças, reproduzindo concepções e atitudes vivenciadas anteriormente e, consequentemente, ensinando como seus professores. Essa problemática foi levantada e constatada já no início das atividades com os AP. Por meio da reflexão, com base em argumentações, discussões, leituras, pesquisas, produção individual e coletiva, em dois momentos, os AP foram provocados: quando foram solicitados a produzirem um novo conceito de ensinar e aprender e quando relutaram em projetarem uma aula (hipotética) de Biologia, usando os recursos computacionais numa perspectiva colaborativa.

No primeiro momento, os AP usaram argumentos tais como "Nada disso resolve", "É um ciclo, começou errado", "[...] não agüento mais estes educadores [...] são utópicos [...]", para demonstrarem quanto estavam descrentes em relação à educação. Quando do planejamento da aula de Biologia, as atitudes de resistência dos AP transparecem em colocações infundadas como: "Não acredito que o computador possa trazere benefícios", "O professor, quando usa muito o computador, está querendo enrolar a aula", "A aula no computador é chata, monótona, não ensina, não tem nada de novo, pra isso não precisa ir a escola", "Deve-se desconfiar do professor que utiliza muito o computador".

Essas posturas se mostraram contraditórias, quando comparadas a registros anteriores (Q1 e discussão sobre o uso pedagógico do computador no ensino de Biologia em sala de aula), ocasiões em que os AP evidenciaram suas crenças nas contribuições que as ferramentas computacionais poderiam dar ao ensino de Ciências e Biologia, facilitando a aprendizagem, especialmente por meio da manipulação de simulações de fenômenos físicos e químicos. Essa contradição se explica visto que dificuldades para alterar o papel do professor apresentam-se além da vontade própria, pois advêm de uma bagagem formativa "que não autorizou criar 
coisas novas e alçar vôos mais desafiadores" (BEHRENS, 1996, p. 62). Daí as resistências à mudança, o que demandou tempo e esforço no sentido de estimular a reflexão, atualmente um elemento defendido como essencial na formação inicial de professores, por inúmeros teóricos (PÉREZ-GÓMEZ, 1992; SCHÖN, 1997; VIANNA; CARVALHO, 2001; FREITAS; VILLANI, 2002; PIMENTA; GHEDIN, 2002; PIMENTA, 2005). Atualmente, na área da educação, a utilização das técnicas colaborativas com o apoio da tecnologia computacional é recomendada por autores como Crook (1996), Alcântara (1999), Bruffee (1999), Cortelazzo (2000), Varella et al. (2002), Behrens (2003), Campos, Santoro e Borges (2003), Valaski (2003) e, ainda, pela Secretaria do Estado da Educação ${ }^{11}$ (BRASIL, 2007), com a criação do Portal Dia-a-dia Educação. Portanto, os cursos de formação devem estimular os AP a refletirem sobre suas concepções e atitudes frente ao uso das ferramentas computacionais numa perspectiva colaborativa, já que o processo reflexivo leva à construção da identidade profissional.

Embora "romper com o velho e buscar o novo, torna-se tarefa desafiadora" (BEHRENS, 1996, p. 32), os futuros professores podem desenvolver novas atitudes e ideias sobre o ensino, se seus professores desenvolverem também novas atitudes (GUNSTONE; NORTHFIELD, 1994). Além disso, concepções se alteram quando a perspectiva é a de um trabalho de reflexão conjunta, debate e autoformação (GIL-PÉREZ; CARVALHO, 2000).

É fato que o aprendizado colaborativo promove a discussão interativa entre estudantes e professores, favorecendo o desenvolvimento do pensamento crítico (ALCÂNTARA, 1999). Assim, emergindo num processo reflexivo conjunto, os AP formularam novos conceitos de ensinar e aprender e concordaram em planejar uma aula de Biologia, usando as ferramentas computacionais de forma colaborativa. Refletindo, conjuntamente, sobre o que faziam, os AP elaboraram novos conceitos de ensinar e aprender, incorporando termos como: construção de conhecimento, mediação, busca, compartilhamento, discussão, situações de aprendizagem, troca de ideias, reflexões, interpretação, elaboração e mudança de atitude. Paralelamente à elaboração desses conceitos, os AP atribuíram ao professor o papel de organizador de situações de aprendizagem, e não mais de transmissor de verdades prontas e acabadas, concebendo o aluno não como simples receptor de informações, mas como um agente ativo na produção e assimilação de novos conhecimentos. Vislumbra-se, nessa atribuição, o esboço de um novo perfil de professor: o professor mediador.

A partir da elaboração dos conceitos de ensinar e aprender e dos papéis atribuídos ao professor e ao aluno, os AP responderam criticamente à questão "Porque é que fazemos o que fazemos na sala de aula" (NÓVOA, 1998, p. 29), colocada como questão central nas discussões sobre a construção da identidade profissional do professor. Observamos que, durante o processo reflexivo, os AP conseguiram visualizar a importância da mediação no processo de ensino-aprendizagem, ou seja, a necessidade do professor, dentro da sala de aula, colocar-se como mediador, se desejar, realmente, formar alunos críticos e autônomos e promover um

${ }^{11}$ Informações obtidas por correspondência enviada aos professores da Rede Estadual de Educação (of. circ. $n^{\circ} .13 / 2007$ - GS $\backslash$ SEED), datada de 10 de outubro de 2007. Assunto: integração de mídias para uso de tecnologias na Educação (recebida via correio). 
ensino com mais competência e habilidade. Mas, mudar a forma de os AP conceberem o ensino, implicou estimulá-los, durante todo o tempo da experiência desenvolvida, a formularem perguntas sobre questões fundamentais, tais como: Qual o significado de ensino e de aprendizagem? O que estou fazendo na sala de aula? E por que estou fazendo?

Estas questões foram refletidas e respondidas pelos AP, não somente durante o processo de construção da (possível nova) identidade de professor (professor mediador), mas também na adesão ao uso pedagógico do computador, uma tecnologia por eles identificada, durante o trabalho de campo realizado (visitas às escolas de Maringá), como subutilizada, particularmente nas escolas públicas, estando à espera de professores interessados e comprometidos com a formação integral dos alunos; professores dispostos a vencer o medo e o comodismo; professores capazes de apostar "em todos os meios e recursos existentes para consolidar a construção do conhecimento” (BEHRENS, 1996, p. 64).

\section{Construção do conhecimento compartilhado}

O professor preparado para vencer os desafios da educação contemporânea - autônomo, articulador, criativo, crítico, inovador, mediador, transformador, aberto ao diálogo, à parceria, ao trabalho conjunto e à aprendizagem colaborativa - deve não apenas dominar o conteúdo que ensina, mas compreender como o conhecimento se constitui historicamente: "Quem sabe, faz; quem compreende, ensina" (NÓVOA, 1998, p. 31). Somente compreendendo o processo de ensino-aprendizagem como "[...] um processo global que envolve, ao mesmo tempo, alguém que aprende, alguém que ensina e a própria relação ensino-aprendizagem" (OLIVEIRA, 2003, p. 57), o professor estará preparado para ensinar, lançando mão de elementos mediadores, instrumentos e signos, para chegar à construção de significados e, consequentemente, elaborar novos conhecimentos. E aprende-se a ensinar, ensinando, ou melhor, aprende-se, fazendo e refletindo na e sobre a prática.

A reflexão sobre a ação é, portanto, fundamental no processo de ensino-aprendizagem (ZEICHNER, 1993; SCHÖN, 1997; FREITAS; VILLANI, 2002; MIZUKAMI, 2002 ; PIMENTA; GHEDIN, 2002), pois permite ao professor articular a situação-problema, definindo metas e meios, com base em suas teorias e convicções. E a condição inovadora e significativa para o desenvolvimento profissional dos docentes é criar espaços de reflexão compartilhada, no qual alunos e professores são aprendizes em busca de solução para as dificuldades e os problemas encontrados, assim como para a produção e assimilação de conhecimentos efetivos.

Segundo Crook (1996) e Souza (2000), o conhecimento socialmente compartilhado é relevante para a aprendizagem. Na pesquisa realizada, observamos que as interações sociais estabelecidas nos grupos durante o painel integrado, o trabalho de campo (pesquisa nas escolas maringaenses) e a aula ministrada no Ensino Médio desempenharam papel fundamental na construção de elementos formativos para a docência, tais como: elaboração e compreensão de novos conceitos (colaboração, aprendizagem colaborativa, uso correto e adequado do computador); desenvolvimento de habilidades/atitudes colaborativas: trabalhar em grupo, solucionar problemas, respeitar opiniões alheias, dividir e organizar tarefas, saber falar e ouvir (comunicação), argumentar e chegar a um consenso, compartilhar ideias e materiais, usar o computador pedagogicamente, responsabilidade, flexibilidade, aceitação, disposição, interesse, tole- 
rância, paciência, humildade, disciplina; reconhecimento da necessidade de se valorizar o uso dos recursos computacionais e o emprego da colaboração, assim como da organização para um bom planejamento de aulas; conhecimento da importância da disposição e interesse do professor para propor novas metodologias e alternativas para o ensino de Biologia.

Em sendo a colaboração a base de uma parceria sólida e produtiva para a construção conjunta do conhecimento (CORTELAZZO, 2000), acreditamos que nossa proposta de projetar uma aula de Biologia (hipotética) sob a perspectiva colaborativa trouxe significativa contribuição para a formação dos AP, já que lhes possibilitou identificar o perfil do professor de Biologia, atribuindo-lhe habilidades/características como: ousadia, mediação, orientação, reflexão, uso de recursos tecnológicos, ativo, dinâmico, comprometido, promotor de raciocínio e da construção de conhecimentos e, sobretudo, que pensa na aprendizagem, e não apenas no ensino. Enfim, um professor, de fato, mediador e colaborativo, que coloca o aluno no centro do processo de ensino-aprendizagem, pois é capaz de "prover meios que possibilitem e estimulem a participação ativa dos alunos na construção de novos conhecimentos [...]" (VALASKI , 2003, p. 7).

Se, conforme afirmam Sloczinski et al. (2000), na metodologia colaborativa, o professor é um elemento-chave na medida em que é responsável por organizar situações de aprendizagem e instigar os alunos para o levantamento de questões pertinentes ao tema estudado, agindo como mediador da relação aluno-objeto e conhecimento-realidade, acredito que nos tornamos esse importante elemento. E se, na proposta colaborativa, o importante é o processo, e não o produto final (JOHNSON; JOHNSON, 1987), provavelmente conseguimos fazer com que os AP entendessem como ocorre o processo de ensino-aprendizagem.

Aderir à metodologia colaborativa implicou, particularmente, a necessidade dos AP repensarem a prática pedagógica e revisarem o papel do professor. E refletir, conjuntamente, sobre esses dois pontos essenciais do processo de ensino-aprendizagem, durante a experiência vivida, levou-os, sem dúvida, a compreenderem melhor a mediação enquanto elemento formativo para a docência. E, naturalmente, a compreensão da mediação passa pelo entendimento do processo de ensino-aprendizagem.

\section{Mediação: aprendendo a aprender}

A investigação didática atual tem destacado al-gumas linhas de ação didático-pedagógica compa-tíveis com propostas educacionais de cunho emancipatório, entre elas, a "aprendizagem do pensar criticamente", que implica o "desenvolvimento de competências cognitivas do aprender a aprender" e de "instrumentos concei-tuais para interpretar a realidade e intervir nela" (LIBÂNEO, 2000, p. 81). Nesta perspectiva, no processo de ensino-aprendizagem, como mediador do conhecimento, o professor faria aprender e aprenderia. A educação se renovaria e avançaria continuamente, provocando um processo ininterrupto de atualização (BEHRENS, 1996). E entendemos que a metodologia colaborativa requer um professor disposto a aprender a aprender, visto que o desenvolvimento humano ocorre durante toda a vida do indivíduo (VYGOTSKY, 1984).

No que diz respeito à formação inicial de professores, concordamos ainda que dois pilares da aprendizagem colaborativa merecem destaque: o aprender a ser e o aprender a fazer (DELORS et al., 1998). O professor autônomo e crítico é criador de situações de aprendiza- 
gem e mediador do processo de desenvolvimento intelectual do aluno. Esse professor não deve apenas conhecer, mas saber o saber-fazer, para interagir com o aluno, facilitando e mediando sua experiência educativa e, ainda, instigando sua imaginação na busca, produção e assimilação de novos conhecimentos.

Segundo Vygotsky (1984), por meio das relações sociais mediadas (psicológicas voluntárias, intencionais ou controladas), pelo uso de instrumentos e signos, o indivíduo adquire e aperfeiçoa conhecimentos. Assim, no processo de interação, mais importante que o professor e/ou o aluno, é o campo interativo criado. E, no caso da pesquisa relatada, o campo interativo criado, durante a prática colaborativa mediada pelo computador, na medida em que reuniu recursos humanos (pesquisadora e alunos professores), ideias de diversos autores e recursos computacionais, conduziu os AP a duas formas realmente importantes de aprendizado: $\mathbf{o}$ aprender a ser e $\mathbf{o}$ aprender a fazer.

$O$ aprender a ser professor mediante a elaboração de pensamentos autônomos e críticos, formulando seus próprios juízos de valor de modo a decidir como agir diante dos desafios propostos (DELORS et al., 1998), ocorreu particularmente durante o desenvolvimento do trabalho de campo (visitas às escolas de Maringá). Os AP aprenderam a ser professores na medida em que elaboraram pensamento crítico e autônomo e formularam juízos sobre a real situação das escolas em relação à informática, registrando diferenças significativas existentes entre escolas públicas e escolas privadas, comportamento, formação e interesse de professores, técnicos e administradores, e dificuldades em manter os laboratórios em funcionamento, e, ainda, elaborando instrumentos concei-tuais para intervir nesta realidade.

A autoavaliação sobre a aula ministrada no Ensino Médio destaca pontos positivos e negativos, e apresenta outras evidências de que os AP aprenderam a ser professores, pois, segundo eles, serviu para

"[...] Provar para nós que dentro da sala de aula muito do que parece impossivel
na verdade é realiqável se bem planejado, se o assunto for dominado, a sala estiver
sob controle e os recursos necessários estiverem disponiveis [...] Na verdade, o que
é essencial é a disposição por parte do professor de se responsabilizar pela tarefa
$[\ldots .] "$.

O aprender a fazer, desenvolvendo aptidões para atuarem como professores com mais competência e habilidade (DELORS et al., 1998), ocorreu durante o planejamento e a realização das aulas de Biologia no computador, sob uma perspectiva colaborativa, na turma de alunos do Ensino Médio. Os AP aprenderam a fazer, desempenhando com competência e habilidade a função de professores mediadores, escolhendo temas, estratégias, procedimentos e recursos para trabalhar a aula e, ainda, conduzindo, auxiliando os alunos na investigação, produção e assimilação de novos conceitos e conhecimentos.

$\mathrm{Na}$ realidade, as modalidades de aprendizado (aprender a ser e aprender a fazer), das quais os AP se apropriaram, foram também analisadas na medida em que discorremos sobre como esses futuros professores chegaram a elaborar novos conceitos de ensinar e aprender e aceitaram o desafio de planejar e ministrar uma aula, utilizando os recursos computacionais sob uma perspectiva colaborativa. Os AP, não somente delinearam o perfil do professor mediador, mas, para concretizar essa experiência prática, assumiram a mediação como fator 
relevante no processo de ensino-aprendizagem, durante a aula de Biologia no Ensino Médio do colégio campo do estágio.

Conforme colocação interessante formulada por uma AP, "o professor mediador é aquele que arrisca, tem coragem, pensa no que está fazendo, como vai fazer e porque está fazendo". É, portanto, aquele que, a partir de saberes da experiência constrói o saber pedagógico, um conhecimento que fundamenta a ação docente, pois permite a interação entre ele e seu aluno, não somente nos contextos da sala de aula, mas também da escola na qual trabalha (AZZI, 2005). Essa construção de saber pedagógico ocorreu, particularmente, no desenvolvimento das aulas no Ensino Médio, quando os AP trabalharam de forma colaborativa com os alunos, usando as ferramentas computacionais pedagogicamente e auxiliando-os em todos os momentos e em todas as necessidades, visando "à construção do conhecimento científico e não apenas uma reprodução", segundo uma AP.

Neste aspecto, são interessantes algumas reflexões dos AP, formuladas no questionário final (Q2), sobre a importância da experiência vivida para a vida profissional futura, tais como: "Aprender a trabalhar de maneira menos individualista"; "Aprender a trabalhar e solucionar problemas em grupo"; "A necessidade de organização para um bom planejamento"; "Mudanças relacionadas ao planejamento das aulas colocando o aluno como foco"; "Capacidade de detectar, abordar e respeitar o conhecimento dos alunos"; "Passei a dar mais importância e me preocupar mais com a interação aluno x professor"; "Valorizar uma maior autonomia dos alunos durante o aprendizado".

Essas reflexões sintetizam evidências de que os AP não se limitaram apenas a aplicar técnicas aprendidas (reprodução), mas aprenderam a construir significados e "a comparar novas estratégias de ação, novos modos de enfrentar e definir problemas" (PÉREZ GÓMEZ, 1997, p. 110). Portanto, podemos inferir que os AP caminharam no sentido de construírem uma identidade profissional e também pessoal, já que "[...] a transformação da prática educativa e do saber do professor está estreitamente ligada à transformação da identidade pessoal e profissional" (CARBONNEAU; HÉTU, 2001, p. 68). Ainda, a identidade profissional “[...] se constrói a partir da significação social da profissão [...] constrói-se também, pelo significado que cada professor, enquanto ator e autor confere à atividade docente [...]" (PIMENTA, 2005, p. 19).

E a disciplina de prática de ensino, mais precisamente, o estágio supervisionado, "[...] é o lócus onde a identidade profissional é gerada, construída, referida; volta-se para o desenvolvimento de uma ação vivenciada, reflexiva e crítica e por isso deve ser planejado gradativa e sistematicamente com essa finalidade" (BURIOLLA, 1999 apud PIMENTA; LIMA, 2004, p. 62). Porém, é preciso destacar que aprender a ensinar é um processo continuo, "[...] não obstante a qualidade dos nossos programas de formação de professores, na melhor das hipóteses, só pode preparar os professores para começar a ensinar" (ZEICHNER, 1993, p. 55). Além disso, é importante considerarmos que aprender a ensinar implica disposição, não medir esforços para vencer os obstáculos. E acreditamos que fizemos isso, durante o decorrer de toda a experiência prática realizada com os AP.

\section{Considerações finais}

Uma síntese dos resultados obtidos na Prática de Ensino realizada - formulada com base nas reflexões constantes nos diários de aula e analisada de acordo com três grupos de 
elementos formativos para a docência -, evidencia que os AP se envolveram no processo, vivenciando-o e refletindo sobre ele, propondo, experimentando, analisando e, sobretudo, percebendo se e como o uso adequado das ferramentas computacionais, dentro da perspectiva colaborativa, pode auxiliar o ensino-aprendizagem de Biologia. A partir desse processo crítico-reflexivo conjunto, sobre o que faziam, como faziam e por que faziam, os AP construíram uma (nova?) identidade de professor, desenvolvendo elementos formativos importantes para a docência, tais como formulação de novos conceitos, atitudes e habilidades, assim como a atribuição de novos papéis ao professor e ao aluno, identificando e assumindo a mediação como fator relevante no processo de ensino-aprendizagem.

Aprenderam a ser professores, elaborando pensamentos críticos e autônomos, formulando juízos sobre a realidade vivida e autoavaliando (a autoavaliação é uma etapa importante para a construção da identidade profissional do professor) a aula dada no Ensino Médio. Aprenderam a fazer, desempenhando, com competência e habilidade, a função de professores mediadores, escolhendo temas, estratégias, procedimentos e recursos para trabalharem a aula ministrada no Ensino Médio. Construíram saber pedagógico ao trabalharem de forma colaborativa com os alunos, usando as ferramentas computacionais pedagogicamente e auxiliandoos em todos os momentos e em todas as necessidades, visando não à reprodução, mas a construção do conhecimento científico.

Em síntese, os AP passaram por significativas mudanças atitudinais com relação ao processo de ensino-aprendizagem e ao papel do professor e, portanto, a vivência colaborativa desenvolvida contribuiu significativamente para a formação inicial de cada um deles, iniciando-os no uso pedagógico do computador dentro de uma perspectiva colaborativa e promovendo o desenvolvimento dos elementos formativos para a docência.

Embora não seja possível afirmar, se e como os conhecimentos e as habilidades formativas adquiridos serão utilizados e/ou aplicados em situações de ensino-aprendizagem futuras, parafraseando Vygotsky (1993), enfatizamos que a formação do professor (aprendizagem da docência) é um processo, cujo início ocorre antes da preparação formal (antes da escola), prossegue ao longo desta e continua durante toda a prática profissional vivenciada (vida do indivíduo). E as "evidências" sugerem que os AP iniciaram a construção de uma identidade de professor.

\section{Referências}

ALCÂNTARA, P. R. Tecnologia multimídia na escola regular e especial. Revista Educação e Tecnologia, Curitiba, v. 4, n. 5, p. 111-131, 1999.

AZZI, S. Trabalho docente: autonomia didática e construção do saber pedagógico. In: PIMENTA, S. G. (Org.). Saberes pedagógicos e atividade docente. 4. ed. São Paulo: Cortez, 2005. p. 35-60.

BEHRENS, M. A. Formação continuada dos professores e a prática pedagógica. Curitiba: Champagnat, 1996.

Projetos de aprendizagem colaborativa num paradigma emergente. In: MORAN, J. M.; MASETTO, M. T.; BEHRENS, M. A. (Orgs.). Novas tecnologias e mediação pedagógica. 7. ed. Campinas: Papirus, 2003. p. 67-132. 
Gianotto, D. E. P.; Diniz, R. E. S.

BRASIL. Integração de mídias para uso de tecnologias na educação. Brasilia: SEED, 2007. (Circular, 13).

BRUFFEE, K. A. Collaborative learning: higter education, interdependence and the authority of knowledge. Baltimore: Johns Hopkins, 1999.

CAMPOS, F. C. A.; SANTORO, F. M.; BORGES, M. R. S. Cooperação e aprendizagem on-line. Rio de Janeiro: DP\&A, 2003.

CARBONNEAU, M.; HÉTU, J. C. Formação prática dos professores e nascimento de uma inteligência profissional. In: PERRENOUD, P.; PAQUAY, L.; ALTET, M.; CHARLIER, E. (Orgs.). Formando professores profissionais: quais estratégias? quais competências? 2. ed. Porto Alegre: Artmed, 2001. p. 67-84.

CONSELHO NACIONAL DE EDUCAÇÃO. Resolução CNE/CP n 1 , de 18 de fevereiro de 2002. Institui Diretrizes Curriculares Nacionais para a Formação de Professores da Educação Básica, em nível superior, curso de licenciatura, de graduação plena. Diário Oficial da União, Brasília, DF, 9 abr. 2002. Seção 1, p. 31.

CORTELAZZO, I. B. C. Colaboração, trabalho em equipe e as tecnologias de comunicação: relações de proximidade em cursos de pós-graduação. 2000. 210f. Tese (Doutorado em Educação) - Faculdade de Educação, Universidade de São Paulo, São Paulo, 2000. Disponível em: < http://www.boaaula.com.br/iolanda/tese/sumtese.htm>. Acesso em: 20 out. 2004.

CROOK, C. Computers and the collaborative experience of learning. New York: Routledge, 1996.

DELORS, J. et al. Educação: um tesouro a descobrir - relatório para Unesco da Comissão Internacional sobre Educação para o século XXI. São Paulo: Cortez/Unesco, 1998.

FIORENTINI, D.; SOUZA JR, A. J.; MELO, G. F. A. Saberes docentes: um desafio para acadêmicos e práticos. In: GERALDI, C. M. G.; FIORENTINI, D.; PEREIRA, E. M. A. (Orgs.). Cartografias do trabalho docente: professor(a) pesquisado(a). 2. ed. Campinas: Mercado das Letras, 2001. p. 307-335.

FREITAS, D.; VILLANI, A. Formação de professores de ciências: um desafio sem limites. Investigações em Ensino de Ciências, Porto Alegre, v. 7, n. 3, 2002. Disponível em: <http://www.if.ufrgs.br/public/ensino/revista.htm>. Acesso em: 31 jan. 2007.

GIANOTTO, D. E. P. Formação inicial de professores:análise de uma prática colaborativa com o uso de computadores. 2008. 289f. Tese (Doutorado em Educação para a Ciência) - Programa de Pós-graduação em Educação para a Ciência, Universidade Estadual Paulista, Bauru, 2008.

GIL-PÉREZ, D.; CARVALHO, A. M. P. Formação de professores de Ciências: tendências e inovações. 4. ed. São Paulo: Cortez, 2000.

GUNSTONE, R. F.; NORTHFIELD, J. Metacognition and learning to teach. International Journal Scienc Education, London, v. 16, n. 5, p. 523-537, 1994. 
Formação inicial de professores de Biologia: ...

JOHNSON, D. W.; JOHNSON, R. T. Learning together and alone: cooperative, competitive, and individualistic learning. New Jersey: Pretence-Hall, 1987.

LIBÂNEO, J. C. Adeus professor, adeus professora?: novas exigências educacionais e profissão docente. 4. ed. São Paulo: Cortez, 2000.

LÜDKE, M.; ANDRÉ, M. E. D. A. Pesquisa em educação: abordagens qualitativas. São Paulo: EPU, 1986.

MASETTO, M. T. Mediação pedagógica e o uso da tecnologia. In: MORAN, J. M.; MASETTO, M. T.; BEHRENS, M. A. (Orgs.). Novas tecnologias e mediação pedagógica. 7. ed. Campinas: Papirus, 2003. p. 133-173.

MENDES, R.; MUNFORD, D. Dialogando saberes: pesquisa e prática de ensino na formação de professores de ciências e biologia. Ensaio, Belo Horizonte, v. 7, n. 3, p. 4 -12, 2005. Disponível em: <www.fae.ufmg.br/ensaio/vol7especial/mendesemunford.pdf>. Acesso em: 3 maio 2006.

MISUKAMI, M. G. (Org). Escola e aprendizagem da docência: processos de investigação e formação. São Carlos: EdUFSCar, 2002.

MIZUKAMI, M. G. N.; REALI, A. M. M. R. (Orgs.). Formação de professores, práticas pedagógicas e escola. São Carlos: EdUSFSCar, 2002.

MORAN, J. M. Ensino e aprendizagem inovadores com tecnologias. Informática na Educação: Teoria e Prática, Porto Alegre, v. 3, n. 1, p. 137-144, 2003 a.

. Gestão inovadora da escola com tecnologias. In: VIEIRA, A. (Org.). Gestão educacional e tecnologia. São Paulo: Avercamp, 2003b. p. 151-164.

NÓVOA, A. Relação escola-sociedade: "novas respostas para um velho problema". In: SERBINO, R. V.; RIBERIO, R.; BARBASA, R. L. L.; GEBRAN, R. A. (Orgs.). Formação de professores. São Paulo: Editora Unesp, 1998. p. 19-39.

OLIVEIRA, M. K. Pensar a educação: contribuições de Vygotsky. In: CASTORINA, J. A.; FERREIRO, E.; LERNER, D.; OLIVEIRA, M. K. (Orgs.). Piaget-Vygotsky: novas contribuições para o debate. 6. ed. São Paulo: Ática, 2003. p. 51-83.

OSPINA, D. P. El diario como estrategia didáctica. 2005. Disponível em: <http:/ / docencia.udea.edu.co/vicedoce/>. Acesso em: 10 jan. 2006.

PALANGANA, I. C. Desenvolvimento e aprendizagem em Piaget e Vygotsky: a relevância social. 3. ed. São Paulo: Plexus, 2001.

PÉREZ GÓMEZ, A. O pensamento prático do professor: a formação do profissional reflexivo. In: NÓVOA, A. (Org.).Os professores e sua formação. Lisboa: Dom Quixote, 1992. p. 93-114.

PERRENOUD, P. Novas competências para ensinar. Porto Alegre: Artes Médicas Sul, 2000 .

PICONEZ, S. C. B. (Coord.). A prática de ensino e o estágio supervisionado. 11. ed. Campinas: Papirus, 2005. 
Gianotto, D. E. P.; Diniz, R. E. S.

PIMENTA, S. G. Formação de professores: identidade e saberes da docência. In: PIMENTA, S. G. (Org.). Saberes pedagógicos e atividade docente. 4. ed. São Paulo: Cortez, 2005. p. 15-34.

.; GHEDIN, E. (Orgs.). Professor reflexivo no Brasil: gênese e crítica de um conceito. 1. ed. São Paulo: Cortez, 2002.

.; LIMA, M. S. L. Estágio e docência. São Paulo: Cortez, 2004.

SCHÖN, D. A. Formar professores como profissionais reflexivos. In: NÓVOA, A. (Org.). Os professores e sua formação. Lisboa: Dom Quixote, 1997. p. 77-91.

SIMIÃO, L. F.; REALI, A. M. M. R. O uso do computador, conhecimento para o ensino e aprendizagem profissional da docência. In: MIZUKAMI, M. G. N.; REALI, A. M. M. R. (Orgs.). Formação de professores, práticas pedagógicas e escola. São Carlos: EdUSFSCar, 2002. p. 127-149.

SLOCZINSKI, H.; LIMA, J. V.; NITSKE, J. A.; POLÔNIA, E.; ZEVE, C. Integração do cd-rom com a internet: ambiente para aprendizagem colaborativa, 2000. Disponível em: <http://www.niee.ufrgs.br/SBC2000/eventos/wie/wie012.pdf>. Acesso em: 17 jan. 2006.

SOUZA, R. R. Aprendizagem colaborativa em comunidades virtuais. 2000. 98f.

Dissertação (Mestrado Engenharia de Produção) - Universidade Federal de Santa Catarina, Florianópolis, 2000.

TAJRA, S. F. Informática na educação: o professor na atualidade. São Paulo: Érica, 2001.

VALASKI, S. A aprendizagem colaborativa com o uso de computadores: uma proposta para a prática pedagógica. 2003. 107f. Dissertação (Mestrado em Educação) Setor de Ciências Humanas e Teologia, Pontifícia Universidade Católica do Paraná, 2003.

VALENTE, J. A. (Org.). Computadores e conhecimento: repensando a educação. 2. ed. Campinas: Unicamp, 1998. p. 1-51.

VARELLA, P. G.; VERMELHO, S. C.; KESKETH, C. G.; SILVA, A. C. C. Aprendizagem colaborativa em ambientes virtuais de aprendizagem: a experiência inédita da PUCPR.

Revista Diálogo Educacional, Curitiba, v. 3, n. 6, p. 11-27, 2002.

VIANNA D. S.; CARVALHO A. M. P. Do fazer ao ensinar ciência: a importância dos episódios de pesquisa na formação de professores. Investigações em Ensino de Ciências, Porto Alegre, v. 6, n. 2, p. 1-22, 2001. Disponível em: <http://www.if.ufrgs.br/ public/ensino/vol6/n2/v6_n2_a1.htm>. Acesso: 14 mar. 2006.

VYGOTSKY, L. S. A formação social da mente: o desenvolvimento dos processos psicológicos superiores. 1. ed. São Paulo: Martins Fontes, 1984.

Pensamento e linguagem. 3. ed. São Paulo: Martins Fontes, 1993.

ZEICHNER, K. M. A formação reflexiva de professores: idéias e práticas. Lisboa: Educa, 1993.

Artigo recebido em outubro de 2009 e aceito em agosto de 2010.

648

Ciência \& Educação, v. 16, n. 3, p. 631-648, 2010 